\title{
Safety and efficacy of pressurized intraperitoneal/ intrathoracic aerosol chemotherapy (PIPAC/PITAC) in patients with peritoneal and/or pleural carcinomatosis: A preliminary experience
}

\author{
Kuchen $\mathrm{N}^{1}$, Cereser $\mathrm{T}^{1}$, Hailemariam $\mathrm{S}^{2}$ and Schoeb $\mathrm{O}^{1 *}$ \\ ${ }^{1}$ Chirurgisches Zentrum Zürich, Klinik Hirslanden, Zurich, Switzerland \\ ${ }^{2}$ Institut für histologische und zytologische Diagnostik AG Aarau, Switzerland
}

\begin{abstract}
Background: Pressurized intracavitary aerosol chemotherapy is a newly developed therapeutic strategy to treat peritoneal and/or pleural carcinomatosis by directly applying antitumor agents into the peritoneal and/or in thoracic space $(\mathrm{PIPAC}=$ pressurized intraperitoneal aerosol chemotherapy, PITAC = pressurized intrathoracic aerosol chemotherapy). According to the current literature these approaches appear to be promising in terms of efficacy and safety as compared to the other standard chemotherapy strategies for advanced stage tumors.
\end{abstract}

Methods: The purpose of our retrospective, monocentric, observational study is to evaluate the postoperative outcomes of PIPAC/PITAC in patients with peritoneal and/or pleural carcinomatosis from several tumor entities; focusing in particular on gastric cancer, ovarian cancer, mesothelioma and colorectal cancer. Other peritoneal/pleural metastatic tumors have also been investigated and are included in the study.

From April 2014 to April 2018 we collected data from 35 patients (17 male, 18 female), aged 29 to 81 years old, and from a total of 68 procedures (47 PIPAC and 21 PITAC).

Each patient underwent a maximum of 4 PIPAC and/or 4 PITAC applications. Doxorubicin/Cisplatin or Oxaliplatin were administered according to tumoral and patient-related characteristics.

Results: In our preliminary results, 13 cases with several PIPAC/PITAC cycles (72.2\%) showed tumor regression (in terms of PCI/EPC score, Ki-67 proliferation rate and/or peritoneal/pleural effusion). Four out of 11 in the PIPAC series (36.4\%) and 4 out of 7 in the PITAC series (57.1\%) showed a reduction of the Peritoneal Carcinomatosis Index (PCI) as well as the Extent of Pleural Carcinomatosis (EPC score). The Ki-67 proliferation rate was lowered in 6 out of 18 cases in the PIPAC/ PITAC series (33.3\%). A reduction of the peritoneal/pleural effusion was observed in 7 of the 18 interventions (38.9\%).

Twenty-two patients died (62.8\%); 10 within 3 months following the first procedure. Thirteen patients $(37.1 \%)$ are still alive today, with a mean survival duration of 424.5 days.

Ten out of 68 procedures (14.7\%) experienced postoperative complications (adverse events, AEs): 4 AEs were most likely related to the administration of intracavitary chemotherapy ( 2 peritoneal chemical toxic reactions, 1 renal failure, 1 severe splanchnic pain) and 6 AEs had an unclear relationship to the chemotherapy (2 airleakages after PITAC with wedge resection in the same operation, 2 intestinal obstructions, 1 bowel perforation with sepsis development and 1 with wound healing problems). One patient died in hospital due to acute on chronic renal failure. The mean length of hospitalization was 8.5 days $(\mathrm{SD}= \pm 8 \mathrm{~d})$. The quality of life of patients at discharge from hospital was satisfactory on the whole.

Conclusions: On the basis of our results we cannot make definitive statements in term of the efficacy of PIPAC/PITAC but we have observed good tolerability of these procedures with positive feedback regarding quality of life. Due to the difficult recruitment of suitable patients (the majority in very late stages of cancer), more time is needed to achieve statistical significance in our findings.

\section{Introduction and Review of the Literature}

Pressurized Intraperitoneal and Pressurized Intrathoracic Aerosol Chemotherapy (PIPAC and PITAC respectively) refer to newly developed therapeutic strategies to treat peritoneal and/or pleural carcinomatosis (PC) by delivering approved i.v. antitumor agents in the peritoneal and/or into the thoracic space (off-label application). Both procedures are performed minimal invasively and must be considered
${ }^{*}$ Correspondence to: Schoeb O, Chirurgisches Zentrum Zürich, Klinik Hirslanden, Zurich, Switzerland, E-mail: os@professorschoeb.ch

Key words: PIPAC, PITAC, peritoneal carcinomatosis, pleural carcinomatosis, pressurized chemotherapy

Received: May 15, 2018; Accepted: May 26, 2018; Published: May 28, 2018 
Kuchen N (2018) Safety and efficacy of pressurized intraperitoneal/intrathoracic aerosol chemotherapy (PIPAC/PITAC) in patients with peritoneal and/or pleural carcinomatosis: A preliminary experience

as a supplement to established therapies as there is insufficient evidence of their impact on the overall survival in patients affected by PC.

The first PIPAC procedures were developed and performed on pig models between the years 2000 and 2012 by Reymond et al. (Department of Surgery, Marienhospital Herne, Ruhr University Bochum, Germany) $[1,2]$. The intention was to apply chemotherapeutic agents as a pressurized aerosol directly into the abdominal cavity, taking advantage of physical properties such as the homogeneous distribution of a gas within a closed space and creating a pressure gradient to overcome the tumor interstitial fluid pressure; a former obstacle in cancer therapy [3]. Their findings showed increased drug distribution and penetration into the peritoneal tissue as compared to peritoneal lavage with a liquid drug solution which results in a higher local drug concentration. These results were then confirmed on human PC ex vivo [4].

Since the experimental procedure has been approved for humans, many studies have been published regarding its efficacy. The literature on this topic was initially poor (see Case Reports by Solass et al., [4], Tempfer et al., [5] and Giger-Pabst et al., [6]) but has improved constantly over the years.

The first significant results came from Tempfer et al., [7]. This cohort study involved 99 patients with a total of 252 PIPAC procedures and focused primarily on gynecological malignancies, especially ovarian cancer. The investigation proved the efficacy and feasibility of PIPAC, especially in terms of safety, quality of life, tolerability and tumor regression. Odendahl et al. [8] found similar results. Following this strategy, in 2017 the Swiss group of Demartines et al., reported the first concrete contribution outside the Reymond's team by analyzing 91 procedures in 24 consecutive patients and obtaining similar results [911]. Alyami et al., also published a paper with analogue conclusions the same year [12] ( $\mathrm{N}=73$, PIPAC procedures 164).

Tumor specific evidence concerning PIPAC in peritoneal carcinomatosis from gastric (Nadiradze et al., [13]), colorectal (Demtroeder et al., [14]) hepatobiliary (Falkenstein et al., [15]) and pancreatic cancer (Sleeman [16], Khosrawipour et al., [17], Graversen et al., [18]) remains limited, most likely due to recruitment difficulties.

The PITAC procedure has only been analyzed in two small publications $[19,20]$.

Parallel to the population studies, research is progressing in order to improve the procedures, as seen in publications by Khosrawipour et al., [17] and Seitenfus et al., [21-23].

Other satellite papers describe the effects on tumor tissues by combining pressurized drug vaporization with hyperthermia [24], electrostatic precipitation [25], irradiation [26-28], nanoparticles [29] or hyperthermal nanoaerosol [30].

More evidence is needed to confirm these primary results. In 2018 an international survey study by Nowacki et al., reported the data summed up from 832 procedures in 349 patients from 15 PIPAC centers worldwide [31]. Their analysis reports a good overall standardization of the procedures, which is a positive basis for future developments.

We expect more high value data in the future due to the creation of an international PIPAC registry [32].

Moreover, many aspects of these new therapies have not yet been clarified, for example the occupational hazard of nebulized drugs on healthcare professionals. Safety measures implemented during PIPAC/PITAC as described by Solass et al., [33] have proven to be in compliance with the European Community working safety laws, but further detailed investigation is needed to confirm the safety of these procedures.

\section{Methods}

\section{Study design}

In this retrospective, monocentric, observational study we collected the data of 35 patients - with a total of 68 procedures (PIPAC/PITAC) - between April 2014 and April 2018. These 35 patients suffer from different peritoneal/pleural metastatic tumors (Table 1) and the trial includes the preliminary results from an ongoing study.

Since February 2016, our ongoing study is a monocentric prospective phase II clinical trial with the official approval of the Institutional Review Board (Kantonale Ethikkommission, Kanton Zurich Switzerland). The goal is to evaluate postoperative outcomes in patients with peritoneal and/or pleural carcinomatosis of at least 50 patients per tumor entity (gastric, ovarian, colorectal cancer and mesothelioma).

The parameters analyzed before, during and after therapy are:

- Ki-67 as cellular marker of proliferation

- Amount of peritoneal/pleural effusion (ml)

- Pleura Carcinomatosis Index (PCI, scale 0-39 points) and the Extent of Pleural Carcinomatosis (EPC, scale 0-9 points) for PIPAC and PITAC, respectively.

\section{Patient characteristics}

We collected data from 35 patients ( 17 male, 18 female), aged 29 to 81 years old, and 68 procedures (47 PIPAC and 21 PITAC).

Inclusion criteria were age over 18 years, confirmed peritoneal/ pleural carcinomatosis, failure of intravenous chemotherapy (tumor progression or recurrence) and positive consent declaration (Table 2). Patients under 18 years old, those not qualifying for a general anesthesia or not able to communicate, and pregnant women were excluded.

Our internal interdisciplinary Tumor Board determined whether the treatment with PIPAC or PITAC was suitable for each patient or not.

Cisplatin/Doxorubicin (resp. $7.5 \mathrm{mg} / \mathrm{m} 2$ body surface in $150 \mathrm{ml}$ $\mathrm{NaCl} 0.9 \%$ and $1.5 \mathrm{mg} / \mathrm{m}^{2}$ in $50 \mathrm{ml} \mathrm{NaCl} 0.9 \%$ ) or Oxaliplatin (92 $\mathrm{mg} / \mathrm{m}^{2}$ ) were administered according to tumor and patient-related characteristics.

Table 1. Patient classification according to tumor type

\begin{tabular}{|c|c|}
\hline Tumor type & Number of patients n (\%) \\
\hline Colorectal cancer & $6(17.1 \%)$ \\
\hline Gastric cancer & $6(17.1 \%)$ \\
\hline Gynecological malignancies & $9(25 \%)$ \\
\hline Hepatobiliary malignancies & $5(14.3 \%)$ \\
\hline Lung cancer (NSLC) & $5(14.3 \%)$ \\
\hline Other & $4(11.4 \%)$ \\
\hline
\end{tabular}

Table 2. Inclusion and Exclusion Criteria of our study

\begin{tabular}{|c|c|}
\hline Inclusion criteria & Exclusion criteria \\
\hline Age $>18$ years old & Age $<18$ years old \\
\hline Diagnosis of peritoneal/pleural carcinomatosis & Pregnant women \\
\hline Failure of standard intravenous chemotherapy & Non-compliance \\
\hline Positive consent declaration & Not qualifying for general anesthesia \\
\hline
\end{tabular}


Kuchen N (2018) Safety and efficacy of pressurized intraperitoneal/intrathoracic aerosol chemotherapy (PIPAC/PITAC) in patients with peritoneal and/or pleural carcinomatosis: A preliminary experience

A maximum of 4 PIPAC and/or 4 PITAC applications was set for each patient.

\section{Therapy: PIPAC and PITAC}

All PIPAC/PITAC were performed at the Centre for Surgery Zurich, Hirslanden Private Hospital Group, according to recommendations by Solass et al., [33].

Each PIPAC/PITAC was remote controlled and the operating room (OR) was equipped with laminar air-flow.

To ensure the safety of the whole OR staff, a team timeout including a dedicated checklist was specially implemented. Intraoperative data collection also followed a standardized protocol.

In the PIPAC procedure (Figure 1), the abdominal cavity was first inflated with carbon dioxide with $12 \mathrm{mmHg}$ pressure and at $37^{\circ} \mathrm{C}$. Two isolating trocars were inserted ( 5 and $12 \mathrm{~mm}$ in diameter).

A diagnostic laparoscopy was then performed to assess the Peritoneal Carcinomatosis Index (PCI, see Sugarbaker et al. [34]) (Figure 2). Any tumor-related fluid was completely suctioned off and measured in $\mathrm{ml}$. Parietal biopsies were taken from all of the abdominal quadrants and used to analyze tumor activity. In a second step, the nebulizer was connected to a high-pressure injector and inserted into the abdomen through a trocar. The pressurized aerosol containing chemotherapy

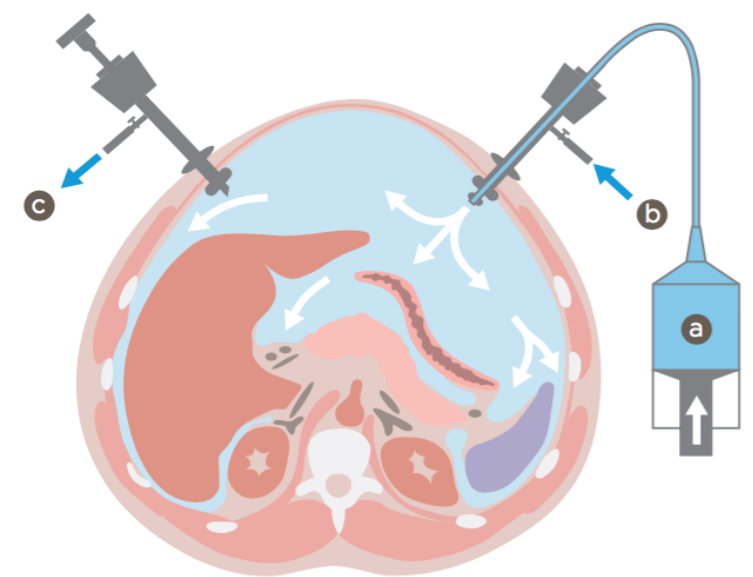

Figure 1. PIPAC procedure: The peritoneal cavity is insufflated with $\mathrm{CO}_{2}$. The chemotherapy agent (a) is vaporized at high pressure within the abdominal cavity (b). The aerosol is suctioned off through another trocar in a closed system (c)
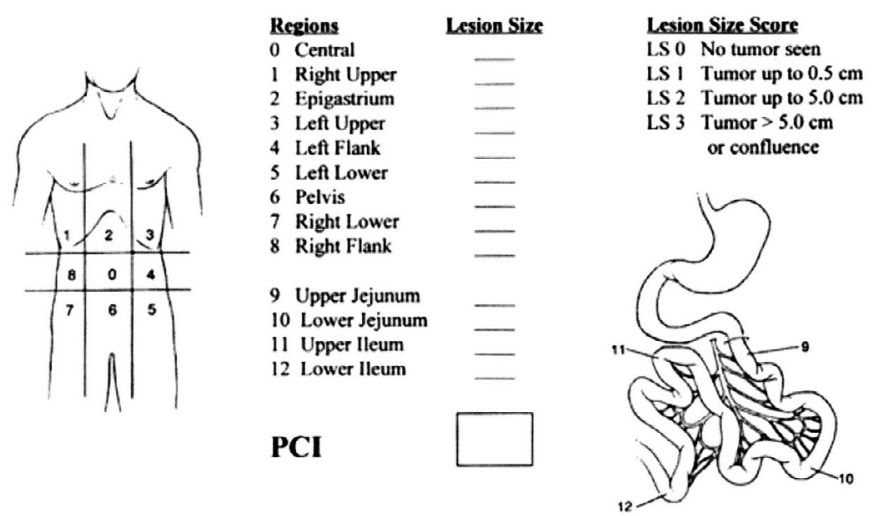

Figure 2. Peritoneal Cancer Index

http://www.hipec.com/knowledge-base/determining-the-peritoneal-cancer-index/ drugs was applied by vaporization in the same manner. A steady state was maintained for 30 minutes at the end of the application to allow for optimal drug absorption into the peritoneal tissue. The toxic aerosol was then removed via a closed exhaust system and the trocars retracted.

In the PITAC procedure, two trocars were placed in the chest wall during one-lung ventilation and connected with the same injector system with $12 \mathrm{mmHg}$ pressure and at $37^{\circ} \mathrm{C}$. The criteria established by Rodriguez-Panadero et al., for measuring pleural carcinomatosis [35] (EPC-score, Extent of Pleural Carcinomatosis-score) was implemented. At the end of the drug vaporization phase, a steady state was maintained for 30 minutes to allow for optimal absorption into the pleural tissue. The toxic aerosol was then removed via a closed exhaust system and the trocars retracted.

\section{Data collection and statistical analysis}

Our data was collected retrospectively over a 4-year-period and stored on a computer database (MS Xcel@).

Descriptive statistics included mean, median and range. Due to the small number of cases, a statistical survey has not been performed.

\section{Results}

Thirty-five consecutive patients were included in our study from April 2014 to April 2018; 17 male and 18 females. 25.7\% were aged over 70 years old with a median age of 54.5 years (29-80) (Table 3 ).

Six patients suffered from colorectal cancer (17.1\%), six from gastric cancer (17.1\%) and nine had gynecological malignancies (25.7\%). Five had hepatobiliary cancer $(14.3 \%)$, five lung cancer $(14.3 \%$, all of them had a non-small cell lung cancer, NSLC) and four suffered from other tumors (pleural mesothelioma, appendiceal mucinous neoplasia, small bowel cancer, Cancer Unknown Primary site) (Table 1). At baseline, 13 patients had organic metastasis $(37.1 \%)$ and 32 had undergone prior radiotherapy/chemotherapy treatment $(91.4 \%)$ (Table 3 ).

The median BMI was $23.4 \mathrm{~kg} / \mathrm{m}^{2}$ (15.4-31.3) at therapy-baseline and did not reduce significantly over time.

Only six patients with BMI lower than $18.5 \mathrm{~kg} / \mathrm{m} 2$ were enrolled in our study (17.1\%) (Table 3).

The total number of interventions was sixty-eight, 47 PIPAC (69.1\%) and 21 PITAC (30.9\%). Each patient could have a maximum of 4 PIPAC and/or 4 PITAC applications. Twenty-five patients received PIPAC only, four patients had PITAC only and 6 patients underwent both PIPAC and PITAC, according to their disease (Table 4).

Twenty-three procedures were performed just once per patient and only eighteen could be repeated at a later date, suggesting that at recruitment, only a few patients were healthy or at a stage in their illness that allowed for serial operations.

In 23 patients $(65.7 \%)$ the therapy had to be discontinued after the first PIPAC/PITAC cycle (Table 5). In the majority of these cases it was due to the deterioration of patient's condition (34.8\%) or death (17.4\%). Four patients stopped the therapy due to a switch to systemic chemotherapy, and two displayed clear tumor progression which required conventional chemotherapy. One case of toxic reaction to the intracavitary chemotherapy was not compatible with further PIPAC cycles. Four patients are currently waiting to continue the PIPAC/ PITAC therapy (17.4\%).

As mentioned above, we observed several parameters in order to evaluate the efficacy of intraperitoneal / intrathoracic chemotherapy 
Kuchen N (2018) Safety and efficacy of pressurized intraperitoneal/intrathoracic aerosol chemotherapy (PIPAC/PITAC) in patients with peritoneal and/or pleural carcinomatosis: A preliminary experience

Table 3. Patient characteristics

\begin{tabular}{|c|c|c|c|}
\hline & All patients $(n=35)$ & 1 PIPAC or PITAC $(n=23)$ & 2 or $>3$ PIPAC or PITAC $(n=18)$ \\
\hline \multicolumn{4}{|l|}{ Demographics } \\
\hline \multirow{5}{*}{$\begin{array}{c}\text { Median age }(\text { years }) \\
\text { Age }>\text { or }=70 \text { years } \\
\text { Gender }(\text { male }) \\
\text { Median BMI }(\mathrm{kg} / \mathrm{m} 2) \\
\text { BMI }<18.5 \mathrm{~kg} / \mathrm{m} 2\end{array}$} & $54.5(28-89)$ & $54.5(29-80)$ & $61(43-79)$ \\
\hline & $9(25.7 \%)$ & $5(21.7 \%)$ & $4(22.2 \%)$ \\
\hline & $17(48.6 \%)$ & $11(47.8 \%)$ & $6(33.3 \%)$ \\
\hline & $23.4(15.4-31.3)$ & $24.2(17.1-31.3)$ & $22.6(15.1-30.1)$ \\
\hline & $6(17.1 \%)$ & $3(13 \%)$ & $4(22.2 \%)$ \\
\hline \multirow[t]{2}{*}{ Prior therapies } & $\begin{array}{c}\text { Radio-/Chemotherapy } \\
\text { Yes }\end{array}$ & \multicolumn{2}{|c|}{$\begin{array}{c}\text { Radio-/Chemotherapy } \\
\text { No }\end{array}$} \\
\hline & $32(91.4 \%)$ & \multicolumn{2}{|c|}{$3(8.6 \%)$} \\
\hline Organic metastasis & $\begin{array}{c}\text { Yes } \\
13(37.1 \%)\end{array}$ & \multicolumn{2}{|c|}{$\begin{array}{c}\text { No } \\
22(62.9 \%)\end{array}$} \\
\hline
\end{tabular}

Table 4. Procedure distribution in our study

\begin{tabular}{|c|c|}
\hline Procedures $(\mathbf{n}=\mathbf{6 8})$ & $\mathbf{n}(\mathbf{\% )}$ \\
\hline PIPAC & $47(69.1 \%)$ \\
\hline PITAC & $21(30.9 \%)$ \\
\hline 1 Cycle (PIPAC or PITAC) & $23(65.7 \%)$ \\
\hline $2+>$ Cycles (PIPAC or PITAC) & $18(34.3 \%)$ \\
\hline Patients (n=35) & $\mathbf{n}(\mathbf{\%})$ \\
\hline PIPAC only & $25(71,4 \%)$ \\
\hline PITAC only & $4(11,4 \%)$ \\
\hline PIPAC and PITAC & $6(17.2 \%)$ \\
\hline
\end{tabular}

Table 5. Reasons for discontinuation of PIPAC / PITAC therapy

\begin{tabular}{|c|c|}
\hline Cause of termination after 1 PIPAC or PITAC Cycle (n=23) & n (\%) \\
\hline General deterioration in condition & $8(34.8 \%)$ \\
\hline Death & $4(17.4 \%)$ \\
\hline Planned systemic therapy & $4(17.4 \%)$ \\
\hline Toxic reaction & $1(4.3 \%)$ \\
\hline Tumor progression & $2(8.7 \%)$ \\
\hline Further PIPAC / PITAC planned & $4(17.4 \%)$ \\
\hline
\end{tabular}

(Table 6). In almost $40 \%$ of the repeated interventions, a regression trend in ascites or pleural effusion was observed. The Ki-67 cell proliferation marker showed a positive effect in $1 / 3$ of the 18 PIPAC/PITAC series. In addition, the PCI and consequently the EPC score was lowered in $45 \%$ of all cases.

The significance of these results, however, is very low due to the small number of patients involved in serial procedures.

Ten PIPAC/PITAC (14.7\%) faced adverse events (AEs) as shown in Table 7. The majority did not exceed Grade IIIb of the Clavien-Dindo classification of postoperative complications (Table 8). One patient died of acute on chronic renal failure two days after the operation.

Only one intraoperative complication occurred during a PIPAC procedure (a minor bowel injury with repair in the same operation). This indicates the high feasibility of this operation thanks to the experienced surgeons and standardized protocols.

The mean length of hospitalization was 8.5 days $(\mathrm{SD}= \pm 8 \mathrm{~d}$ ). The quality of life in patients at time of discharge from hospital was satisfactory on the whole but has not been included in our findings.

At present, thirteen out of thirty-five patients (37.1\%) are still alive with a mean survival of 424,5 days (25-987). Twenty-two patients died (mean survival 189.6 days (2-625)), 10 of them within 3 months following the first procedure (Table 9).

\section{Discussion and conclusion}

There is established pharmacokinetic evidence that intraperitoneal drug administration is advantageous in patients with peritoneal cancer. Intraperitoneal drug administration is usually well tolerated and may improve survival in Stage IV gastric, ovarian and colorectal cancer. Patients especially suitable for supplementary treatment option such as PIPAC or PITAC are those with small disease volume, a stable general condition, normal food intake and well-functioning bowel movements.

The cohort presented here, in contrast, is a summary of different cases with very heterogenous etiologies. There is a very broad spectrum not only of primary cancers, but also the general health status of the patients as shown in our table.

The majority of the cases presented in this study were already at a very advanced stage of cancer, all had undergone intraperitoneal or thoracic operations and most of have an extended history of various courses of chemotherapy.

The results are therefore worse - in contrast to other PIPAC and PITAC series - and not as promising. Nevertheless, in all patients with more than two PIPAC/PITAC-Cycles a potential benefit in terms of reduction of the proliferation rate (Ki67) and ascites or thoracic effusion was documented in $72.2 \%$ of the cases. One can also assume a potential benefit for survival time and improved quality of life for the remaining lifespan. 
Kuchen N (2018) Safety and efficacy of pressurized intraperitoneal/intrathoracic aerosol chemotherapy (PIPAC/PITAC) in patients with peritoneal and/or pleural carcinomatosis: A preliminary experience

Table 6. Intraoperative findings

\begin{tabular}{|c|c|c|c|}
\hline & $\begin{array}{l}\text { First operation } \\
\text { Mean (Range) }\end{array}$ & $\begin{array}{l}\text { Last operation } \\
\text { Mean (Range) }\end{array}$ & $\begin{array}{l}\text { Positive effect after several PIPAC/PITAC- } \\
\text { Cycles }\end{array}$ \\
\hline $\begin{array}{l}\text { Peritoneal Carcinomatosis Index (PCI) } \\
\text { (scale } 0-39 \text { points) }\end{array}$ & $12.5(0-25)$ & $11(0-22)$ & $\begin{array}{c}4 \text { out of } 11 \text { PIPAC } \\
(36.4 \%)\end{array}$ \\
\hline $\begin{array}{l}\text { Extent of Pleural Carcinomatosis (EPC) } \\
\text { (scale } 0-9 \text { points) }\end{array}$ & $4.5(0-9)$ & $4.5(0-9)$ & $\begin{array}{c}4 \text { out of } 7 \text { PITAC } \\
(57.1 \%)\end{array}$ \\
\hline Ki-67, cell proliferation index (\%) & $47.5(5-90)$ & $45(10-80)$ & 6 out of 18 PIPAC/PITAC (33.3\%) \\
\hline Ascites (ml) & $3000(0-6000)$ & $4300(0-8600)$ & $\begin{array}{l}4 \text { out of } 11 \text { PIPAC } \\
(36.4 \%)\end{array}$ \\
\hline Pleural effusion (ml) & $900(0-1800)$ & $450(0-900)$ & $\begin{array}{c}3 \text { out of } 7 \text { PITAC } \\
(42.9 \%)\end{array}$ \\
\hline
\end{tabular}

Table 7. Adverse events (AEs), a description

\begin{tabular}{|c|c|c|c|}
\hline & Adverse event (n) & $\begin{array}{l}\text { Severity of postoperative complications } \\
\text { according to the Clavien-Dindo } \\
\text { classification }\end{array}$ & $\begin{array}{l}\text { Therapy of the adverse } \\
\text { event }\end{array}$ \\
\hline Intraoperative complications $(\mathrm{n}=1 ; 1.5 \%)$ & Small bowel lesion $(\mathrm{n}=1)$ & & Direct repair within the PIPAC procedure \\
\hline Postoperative complications $(\mathrm{n}=10 ; 14.7 \%)$ & $\begin{array}{l}\text { Small bowel obstruction }(\mathrm{n}=2) \\
\text { Small bowel perforation }(\mathrm{n}=1) \\
\text { Prolonged air-leakage }(\mathrm{n}=2) \\
\text { Severe splanchnic pain }(\mathrm{n}=1) \\
\text { Toxic reaction to the chemotherapy }(\mathrm{n}=2) \\
\\
\text { Acute on chronic renal failure }(\mathrm{n}=1) \\
\text { Wound healing problems }(\mathrm{n}=1)\end{array}$ & $\begin{array}{l}\text { Grade II - IIIb } \\
\text { Grade IIIb } \\
\text { Grade I } \\
\text { Grade IIIa } \\
\text { Grade II - IIIa } \\
\text { Grade IIIa - V } \\
\text { Grade I }\end{array}$ & $\begin{array}{l}\text { Revision laparotomy }(\mathrm{n}=1) \text {, conservative }(\mathrm{n}=3) \\
\text { Revision laparotomy, Antibiotics } \\
\text { Conservative treatment } \\
\text { Splanchnic nerve block } \\
\text { Drainage and antibiotics ( } \mathrm{n}=1) \text {, antibiotics } \\
\text { only }(\mathrm{n}=1) \\
\text { Hydration, Dialysis } \\
\text { Prolonged wound care }\end{array}$ \\
\hline \multicolumn{4}{|l|}{ Deaths } \\
\hline In-hospital deaths $(\mathrm{n}=1 ; 1.5 \%)$ & Acute on chronic renal failure & & \\
\hline
\end{tabular}

Table 8. Clavien-Dindo classification of surgical complications [36]

\begin{tabular}{|c|l|}
\hline \multicolumn{2}{|c|}{ Clavien-Dindo classification of surgical complications } \\
\hline Grade & Definition \\
\hline I & $\begin{array}{l}\text { Any deviation from the normal postoperative course without need of intervention beyond the administration of antiemetics, antipyretics, analgesics, diuretics, electrolytes } \\
\text { and physical therapy (includes drained cutaneous infections without general anesthesia) }\end{array}$ \\
\hline II & Complication requiring pharmacological treatment with other medicines beyond those used for the Grade I complications \\
\hline III & Complication requiring surgical, endoscopic or radiological intervention, with (III-a) or without (III-b) general anesthesia \\
\hline IV & Life-threatening complication requiring admission to intensive care unit, with single organ dysfunction (including dialysis) (IV-a) or with multiple organ dysfunction (IV-b) \\
\hline V & Death \\
\hline
\end{tabular}

Table 9. Survival in days since the start of PIPAC/PITAC therapy (mean)

\begin{tabular}{|c|c|}
\hline $\begin{array}{c}\text { Survival following first PIPAC/PITAC } \\
\text { Cycle }\end{array}$ & Days \\
\hline Alive $(\mathrm{n}=13)$ & $424.5(25-987)$ \\
\hline Dead $(\mathrm{n}=22)$ & $189.6(2-625)$ \\
\hline Dead within 30 postoperative days $(\mathrm{n}=10)$ & \\
\hline
\end{tabular}

On the other hand, the study is a proof of the patient safety of aerosol chemotherapy in the peritoneal and the thoracic cavities. Even in very advanced stage of disseminated cancer, the application could be performed and was well tolerated in all cases but one. This patient was suffering from chronic renal failure and died at the second postoperative day due to acute on chronic renal failure.

In all other cases the hospital stay was almost uneventful and did not influence the outcome of PIPAC or PITAC. A toxic reaction to the chemotherapy occurred in two cases but these were resolved without any long-term consequences.

Access to the chest or peritoneum was not a problem in most cases even if the patient had already undergone surgery - including major surgery such as extended cytoreduction or HIPEC or a combination of both. In one case, a small bowel lesion occurred during introduction of the optic trocar. The injury was closed with two laparoscopic sutures and PIPAC administration was carried out without any other complications.
In conclusion, the presented heterogenous cohort demonstrates different important aspects of PIPAC and PITAC. First of all, the administration can be performed with low risk and is well tolerated, even in patients with advanced disease and reduced general health conditions. The heterogeneity of the cohort collective and the challenge of finding patients at an earlier stage of the disease made it difficult to obtain more accurate results.

PIPAC and PITAC appear to be efficient treatment options in a fairly large group of cancer patients. Further research is needed to generate more effective arguments for patient selection and to define the most suitable time to start with - or use as a neo-adjuvant or additive therapy - in cancers which have spread to body cavity surfaces.

\section{References}

1. Reymond MA, Hu B, Garcia A, Reck T, Köckerling F, et al (2000) Feasibility of therapeutic pneumoperitoneum in a large animal model using a microvaporisator. Surg Endosc 14: 51-55. [Crossref]

2. Solaß W, Hetzel A, Nadiradze G, Sagynaliev E, Reymond MA (2012) Description of a novel approach for intraperitoneal drug delivery and the related device. Surg Endosc 26: 1849-1855. [Crossref]

3. Solass W, Herbette A, Schwarz T, Hetzel A, Sun JS, et al. (2012) Therapeutic approach of human peritoneal carcinomatosis with Dbait in combination with capnoperitoneum: proof of concept. Surg Endosc 26: 847-852. [Crossref]

4. Solass W, Kerb R, Mürdter T, Giger-Pabst U, Strumberg D, et al. (2014) Intraperitoneal chemotherapy of peritoneal carcinomatosis using pressurized aerosol as an alternative to liquid solution: first evidence for efficacy. Ann Surg Oncol 21: 553-559. [Crossref] 
Kuchen N (2018) Safety and efficacy of pressurized intraperitoneal/intrathoracic aerosol chemotherapy (PIPAC/PITAC) in patients with peritoneal and/or pleural carcinomatosis: A preliminary experience

5. Tempfer CB, Solass W, Buerkle B, Reymond MA (2014) Pressurized intraperitoneal aerosol chemotherapy (PIPAC) with cisplatin and doxorubicin in a woman with pseudomyxoma peritonei: A case report. Gynecol Oncol Rep 18:32-5. [Crossref]

6. Giger-Pabst U, Solass W, Buerkle B, Reymond MA, Tempfer CB, et al. (2015) Lowdose pressurized intraperitoneal aerosol chemotherapy (PIPAC) as an alternative therapy for ovarian cancer in an octogenarian patient. Anticancer Res 35: 2309-2314. [Crossref]

7. Tempfer CB, Rezniczek GA, Ende P, Solass W, Reymond MA (2015) Pressurized Intraperitoneal Aerosol Chemotherapy with Cisplatin and Doxorubicin in Women with Peritoneal Carcinomatosis: A Cohort Study. Anticancer Res 35: 6723-6729. [Crossref]

8. Odendahl K, Solass W, Demtröder C, Giger-Pabst U, Zieren J, et al. (2015) Quality of life of patients with end-stage peritoneal metastasis treated with Pressurized IntraPeritoneal Aerosol Chemotherapy (PIPAC). Eur J Surg Oncol 41: 1379-1385. [Crossref]

9. Hübner M, Teixeira Farinha H, Grass F, Wolfer A, Mathevet P, et al. (2017) Feasibility and Safety of Pressurized Intraperitoneal Aerosol Chemotherapy for Peritoneal Carcinomatosis: A Retrospective Cohort Study. Gastroenterol Res Pract 2017: 6852749. [Crossref]

10. Teixeira Farinha H, Grass F, Kefleyesus A, Achtari C, Romain B, et al. (2017) Impact of Pressurized Intraperitoneal Aerosol Chemotherapy on Quality of Life and Symptoms in Patients with Peritoneal Carcinomatosis: A Retrospective Cohort Study. Gastroenterol Res Pract 2017: 4596176. [Crossref]

11. Teixeira Farinha H, Grass F, Pache B, Demartines N, et al. (2018) Inflammatory Response and Toxicity After Pressurized IntraPeritoneal Aerosol Chemotherapy. $J$ Cancer 9: 13-20. [Crossref]

12. Alyami M, Gagniere J, Sgarbura O, Cabelguenne D, Villeneuve L, et al. (2017) Multicentric initial experience with the use of the pressurized intraperitoneal aerosol chemotherapy (PIPAC) in the management of unresectable peritoneal carcinomatosis. Eur J Surg Oncol 43: 2178-2183. [Crossref]

13. Nadiradze G, Giger-Pabst U, Zieren J, Strumberg D, Solass W, et al. (2016) Pressurized Intraperitoneal Aerosol Chemotherapy (PIPAC) with Low-Dose Cisplatin and Doxorubicin in Gastric Peritoneal Metastasis. J Gastrointest Surg 20: 367-373. [Crossref]

14. Demtröder C, Solass W, Zieren J, Strumberg D, Giger-Pabst U, et al. (2016) Pressurized intraperitoneal aerosol chemotherapy with oxaliplatin in colorectal peritoneal metastasis. Colorectal Dis 18: 364-371. [Crossref]

15. Falkenstein TA, Götze TO, Ouaissi M, Tempfer CB, et al. (2018) First Clinical Data of Pressurized Intraperitoneal Aerosol Chemotherapy (PIPAC) as Salvage Therapy for Peritoneal Metastatic Biliary Tract Cancer. Anticancer Res 38: 373-378. [Crossref]

16. Sleeman JP (2017) PIPAC puts pressure on peritoneal metastases from pancreatic cancer. Clin Exp Metastasis 34: 291-293. [Crossref]

17. Khosrawipour T, Khosrawipour V (2017) Pressurized Intra Peritoneal Aerosol Chemotherapy in patients suffering from peritoneal carcinomatosis of pancreatic adenocarcinoma. PLoS One 19: 12 [Crossref]

18. Graversen M, Detlefsen S, Bjerregaard JK, Pfeiffer P, Mortensen MB (2017) Peritoneal metastasis from pancreatic cancer treated with pressurized intraperitoneal aerosol chemotherapy (PIPAC). Clin Exp Metastasis 34: 309-314. [Crossref]

19. Giger-Pabst U, Demtröder C, Falkenstein TA, Ouaissi M, Götze TO, et al. (2018) Pressurized IntraPeritoneal Aerosol Chemotherapy (PIPAC) for the treatment of malignant mesothelioma. MC Cancer. 2018 Apr 18;18(1):442. [Crossref]

20. Robella M, Vaira M, Borsano A, Mossetti C, DE Simone M (2018) Low-dose Pressurized Intrathoracic Aerosol Chemotherapy (PITAC) as an Alternative Therapy for Pleuropulmonary Involvement in Pseudomyxoma Peritonei. Anticancer Res 38: 929-932. [Crossref]
21. Khosrawipour V, Khosrawipour, Falkenstein TA, Diaz-Carballo D, Förster E, et al. (2016) Evaluating the Effect of Micropump (C) Position, Internal Pressure and Doxorubicin Dosage on Efficacy of Pressurized Intra-peritoneal Aerosol Chemotherapy (PIPAC) in an Ex Vivo Model. Anticancer Res 36: 4595-600. [Crossref]

22. Seitenfus R, Ferreira PRW, Santos GOD, Alves RJV, Kalil AN, et al. (2017) A prototype single-port device for pressurized intraperitoneal aerosol chemotherapy. Technical feasibility and local drug distribution. Acta Cir Bras 32: 1056-1063. [Crossref]

23. Khosrawipour V, Khosrawipour T, Diaz-Carballo D, Förster E, et al. (2016) Exploring the Spatial Drug Distribution Pattern of Pressurized Intraperitoneal Aerosol Chemotherapy (PIPAC). Ann Surg Oncol 23: 1220-1224. [Crossref]

24. Jung do H, Son SY, Oo AM, Park YS, Shin DJ (2016) Feasibility of hyperthermic pressurized intraperitoneal aerosol chemotherapy in a porcine model. Surg Endosc 30: 4258-4264. [Crossref]

25. Kakchekeeva T, Demtröder C, Herath NI, Griffiths D, Torkington J, et al. (2016) In Vivo Feasibility of Electrostatic Precipitation as an Adjunct to Pressurized Intraperitoneal Aerosol Chemotherapy (ePIPAC). Ann Surg Oncol 23: 592-598. [Crossref]

26. Khosrawipour V, Giger-Pabst U, Khosrawipour T, Pour YH, Diaz-Carballo D, et al. (2016) Effect of Irradiation on Tissue Penetration Depth of Doxorubicin after Pressurized Intra-Peritoneal Aerosol Chemotherapy (PIPAC) in a Novel Ex-Vivo Model. J Cancer 7: 910-914. [Crossref]

27. Khosrawipour V, Bellendorf A, Khosrawipour C, Hedayat-Pour Y, Diaz-Carballo D, et al. (2016) Irradiation Does Not Increase the Penetration Depth of Doxorubicin in Normal Tissue After Pressurized Intra-peritoneal Aerosol Chemotherapy (PIPAC) in an Ex Vivo Model. In Vivo 30: 593-597. [Crossref]

28. Khosrawipour V, Khosrawipour T, Hedayat-Pour Y, Diaz-Carballo D, Bellendorf A, et al. (2017) Effect of Whole-abdominal Irradiation on Penetration Depth of Doxorubicin in Normal Tissue After Pressurized Intraperitoneal Aerosol Chemotherapy (PIPAC) in a Post-mortem Swine Model. Anticancer Res 37:1677-1680. [Crossref]

29. Nowacki M, Peterson M, Kloskowski T, McCabe E, Guiral DC, et al. (2017) Nanoparticle as a novel tool in hyperthermic intraperitoneal and pressurized intraperitoneal aerosol chemotheprapy to treat patients with peritoneal carcinomatosis. Oncotarget 31:78208-78224. [Crossref]

30. Göhler D, Große S, BellendorfA, Falkenstein TA, Ouaissi M, et al. (2017) Hyperthermic intracavitary nanoaerosol therapy (HINAT) as an improved approach for pressurised intraperitoneal aerosol chemotherapy (PIPAC): Technical description, experimental validation and first proof of concept. Beilstein J Nanotechnol 18:2729-2740. [Crossref]

31. Nowacki M, Alyami M, Villeneuve L, Mercier F, Hubner M, et al. (2018) Multicenter comprehensive methodological and technical analysis of 832 pressurized intraperitoneal aerosol chemotherapy (PIPAC) interventions performed in 349 patients for peritoneal carcinomatosis treatment: An international survey study. Eur J Surg Oncol 18: 30674 30677. [Crossref]

32. ClinicalTrials.gov identifier (NCT number): NCT03210298.

33. Solass W, Giger-Pabst U, Zieren J, Reymond MA (2013) Pressurized intraperitoneal aerosol chemotherapy (PIPAC): occupational health and safety aspects. Ann Surg Oncol 20: 3504-3511. [Crossref]

34. Sugarbaker PH, Jablonski KA (1995) Prognostic features of 51 colorectal and 130 appendiceal cancer patients with peritoneal carcinomatosis treated by cytoreductive surgery and intraperitoneal chemotherapy. Ann Surg 221: 124-132. [Crossref]

35. Rodriguez-Panadero, J Lopez-Mejias. Survival time of patients with pleural metastatic carcinoma predicted by glucose and $\mathrm{pH}$ studies. Chest 95: 320-324. [Crossref]

36. Dindo D, Demartines N, Clavien PA (2004) Classification of surgical complications: a new proposal with evaluation in a cohort of 6336 patients and results of a survey. Ann Surg 240: 205-213. [Crossref]

Copyright: (C2018 Kuchen N. This is an open-access article distributed under the terms of the Creative Commons Attribution License, which permits unrestricted use, distribution, and reproduction in any medium, provided the original author and source are credited. 